\title{
Validation of a computational model versus a bench top model of an aortic dissection model
}

\author{
Khalil Khanafer ${ }^{1,2}$, Marty S. Schlicht ${ }^{2}$, Kambiz Vafai $^{3}$, Saurabh Prabhakar ${ }^{4}$, Mohamed Gaith ${ }^{1}$ \\ 1. Department of Mechanical Engineering, Australian College of Kuwait, Kuwait. 2. Department of Biomedical Engineering, \\ University of Michigan, Ann Arbor, USA. 3. Department of Mechanical Engineering, University of California, USA. 4. Ansys \\ Inc, Technical Support \& Services, India.
}

Correspondence: Kambiz Vafai. Address: Department of Mechanical Engineering, University of California, Riverside, CA, 92521, USA. Email: vafai@engr.ucr.edu

Received: August 18, 2015

DOI : $10.5430 /$ jbei.v2n1p82
Accepted: October 13, 2015

URL: http://dx.doi.org/10.5430/jbei.v2n1p82

\section{Abstract}

Objective: The aim of this investigation was to validate our numerical model of type B aortic dissection with our experimental results from a bench-top-model.

Methods: Various numerical meshes were constructed using a finite-volume based computational fluid dynamics (CFD) solver (ANSYS Fluent 15) to simulate pulsatile flow and pressure in dissected aorta models. The $\kappa-\omega$ Shear Stress Transport (SST) turbulence model was imbedded. All simulations were carried out for four cardiac cycles to achieve a periodic solution, and the results obtained in the fourth cycle were used in the validation.

Results: We validated the numerical results, for several tear size and location, with our experimental data. CFD results of type B aortic dissection with various tear size and location were strongly correlated with the in vitro results.

Conclusions: CFD tools have a potential role in evaluating different scenarios and aortic dissection configurations.

\section{Key words}

Aortic dissection, Computational fluid dynamics, In vitro model

\section{I ntroduction}

Acute aortic dissection is a life threatening condition with a death rate of $1 \%-2 \%$ per hour after symptom onset ${ }^{[1]}$. Aortic dissection is a tear within the inner layer of the aortic wall that allows blood under pressure to advance within the media as a dissecting intramural hematoma. The result is a two lumen channel separated by a septum or dissection flap that consists of intima and part of the media. Aortic dissection may propagate either distally or proximally from the entry tear and may involve vessel branches ${ }^{[2,3]}$. Most dissections have additional distal tear(s) through which blood may enter and egress the false lumen. This double lumen arrangement creates the mechanical conditions responsible for both acute complications (visceral and lower extremity ischemia) and chronic ones (development of thoracic aortic aneurysms). 
Numerical simulations of a type B aortic dissection present special complexities. There are two parallel flow channels of different outflows and elastic properties. The communication between the two channels ("tears") may be single or multiple and of variable sizes. In recent years, numerical methods for modeling the aorta have been increasingly used in the study of its diseases ${ }^{[4-9]}$ and its treatment with medical devices ${ }^{[10-15]}$. Few studies have focused on modeling the hemodynamics of aortic dissection. Tse et al. ${ }^{[16]}$ used computational fluid dynamics (CFD) to study the hemodynamics of development of a dissecting aneurysm. This study used a patient-specific dissected aorta and assumed rigid aortic walls. Blood flow was assumed laminar and incompressible Newtonian fluid. Velocity and pressure waveforms applied at different locations of the aortic model were obtained from various articles in the literature. Fan et al. ${ }^{[17]}$ used CFD in an idealized geometry of an aortic dissection model to assess the effect of three features: ratio of the area of the false lumen to that of the true lumen, size of the reentry tear, and position of the reentry tear, on the post-operative risk analysis after endovascular stent graft deployment. To simplify their model, the aortic wall and the intimal flap were assumed rigid and the renal, celiac, superior mesenteric artery and iliac arteries were not represented. Pulsatile velocity inlet and pulsatile pressure outlet waveforms were used.

Soudah et al. ${ }^{[18]}$ applied CFD methodology to the characterization of hemodynamics in an idealized geometry of chronic aortic dissection (rigid flap) and validated it with in vitro results ${ }^{[19]}$. No branches were included in their model. Timedependent velocity and pressure waveforms taken from the in vitro experiments 19 were applied as boundary conditions to the model. There were large differences in the results obtained from CFD simulations and experimental measurements ${ }^{[19]}$ when they compared the results of their flexible physical model (The true lumen wall was made of silicone and the false lumen outer wall of latex) with their rigid CFD model. Karmonik et al. ${ }^{[20]}$ provided CFD simulations with aortic dissection models derived from MRI image data to study the pressure changes in a laminar numerical model when covering entry and exit tears and removing the intra-arterial septum. Their boundary conditions were unrealistic: they assumed zero pressure outlet boundary conditions for the innominate, left common carotid, left subclavian, celiac and superior mesenteric and renal arteries. Pressure is pulsatile and cannot be assumed constant at these locations. Khanafer and Berguer ${ }^{[21]}$ showed how dissections develop and progress in an idealized simplified descending aorta numerical model: the media layer undergoes larger wall stress than the intima and adventitia layers which is an important factor in the development of aortic dissections.

Advances in computational techniques have provided us with an essential tool for the investigation of diseases such as aortic aneurysm and dissection, where the integrity of the aortic wall is determined by hemodynamic factors. To the best of our knowledge, there are only a limited number of numerical studies in the literature to model flow and mechanical stresses in aortic dissection and they all consisted of studies using either non-synchronized (i.e. from different sources) boundary conditions at the inlet and outlet locations of the model or geometries of aortic dissections without branches. The aim of this investigation was to build a verifiable numerical model of aortic dissection against our experimental results of a bench-top-model of a type B aortic dissection for various tear sizes and location. Numerical analysis permits the computation of mechanical forces in structures of irregular geometry or submitted to variable and extreme physical conditions. A clear advantage of numerical models over their animal counterparts is their ability to test multiple variables simultaneously. Animal models are limited since they only allow for testing of a few variables per experiment and animal. In contrast, a numerical model can display the effects of many variables, as well as the effects of these variables among themselves.

\section{Methods}

\subsection{Mathematical formulation}

Three-dimensional Computer Aided Design (CAD) software (Solid Works Corp.) was used in this investigation to create an aortic dissection model with normal human geometry. To this model, we assigned variable tear sizes and location as shown in Table 1. A schematic diagram of the model is shown in Figure 1a. The physical model used in this validation had 
the same geometry and dimensions as the numerical model. An ex-vivo dynamic flow circuit was constructed to mimic the human circulatory system. The circuit consisted of a pulsatile pump, a compliance chamber, the aortic dissection model, and a collecting system. True lumen wall was made of a glass, while the false lumen, flap, and branches were constructed with Polytetrafluoroethylene (PTFE) (Elastic modulus $=9 \mathrm{MPa}$ ). We used water as a perfusion fluid flowing through the numerical and phantom models, with a density of $1,000 \mathrm{~kg} / \mathrm{m}^{3}$ and a dynamic viscosity of $8.90 \times 10^{-4} \mathrm{~Pa} \cdot \mathrm{s}$. Moreover, water was assumed to be incompressible, homogeneous and Newtonian. No-slip condition was applied at the aortic wall.

Table 1. Summary of the models used in this investigation

\begin{tabular}{lll}
\hline Model & Proximal Tear $\left(\mathbf{m m}^{2}\right)$ & Distal Tear $\left(\mathbf{m m}^{2}\right)$ \\
\hline Model-1 & 65 & 0 \\
Model-2 & 65 & 20 \\
Model-3 & 65 & 40 \\
Model-4 & 145 & 40 \\
Model-5 & 145 & 90 \\
\hline
\end{tabular}

Due to the high Reynolds number within the model, a turbulence model was included in our numerical simulation. Considering the inlet diameter of the aortic model is $21.4 \mathrm{~mm}$ and the peak velocity of $16.7 \mathrm{~cm} / \mathrm{s}$ (for $145 \mathrm{~mm}^{2}$ proximal $40 \mathrm{~mm}^{2}$ distal tears bench-top model), the peak Reynolds number was calculated as 4,109.6, while the time-averaged Reynolds number is 2,891.6, indicating the flow within the aorta involves laminar, transitional, and turbulent regimes. Turbulence in blood flow may influence flow and pressure patterns, and wall shear stress ${ }^{[22]}$. For example, in the case of aneurysm, Khanafer et al. ${ }^{[23]}$ and Berguer et al. ${ }^{[24]}$ showed that turbulence induced by sudden expansion of the flow stream results in wall vibration with additional stresses acting on the aneurysm wall that may be responsible for further aortic dilation. Cyclic turbulent stresses are known to alter the structure and integrity of the arterial wall. Large eddies induce vibrations at frequencies associated with the dilation of arteries. The smallest turbulent eddies (Kolmogorov microscale), which are a function of the kinematic viscosity of blood and turbulent dissipation rate, can mechanically damage the blood cells and the components of the arterial wall ${ }^{[23]}$. The Navier-Stokes equations for 3D time-dependent flows, together with the shear-stress transport (SST) $k$ - $\omega$ model were solved using a finite-volume based CFD solver, ANSYS Fluent 15.0. The SST $k$ - $\omega$ model was developed by Menter ${ }^{[25]}$ to effectively combine the robust and accurate formulation of the $k$ - $\omega$ Wilcox model ${ }^{[26]}$ in the near-wall region with the free-stream independent of the $k$ - $\varepsilon$ model ${ }^{[27]}$ in the far field. The bioheat aspects can be established through the analytical results given in Wang K et al. ${ }^{[28]}$.

Figure 1. (a) Schematic diagram of the dissection model, (b) Mesh.

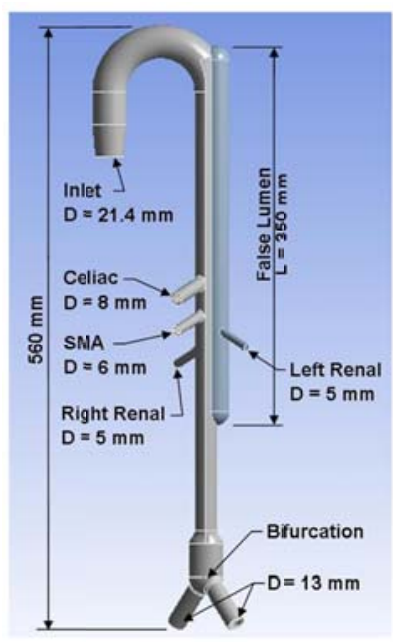

(a)

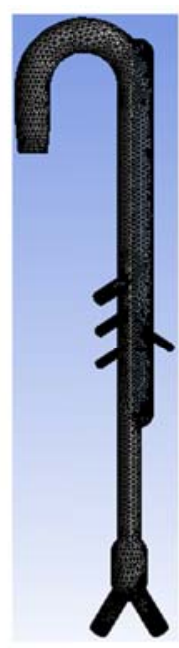

(b) 


\subsection{Boundary conditions}

Time-dependent pressure waveforms and velocities obtained from our in vitro experiments (see Figure 2) were obtained at the inlet and outlet branches of the fluid domain (see Figure 1). Total pressure was applied at the inlet of the numerical model while static pressures were applied at renal, celiac, superior mesenteric artery and iliac arteries.

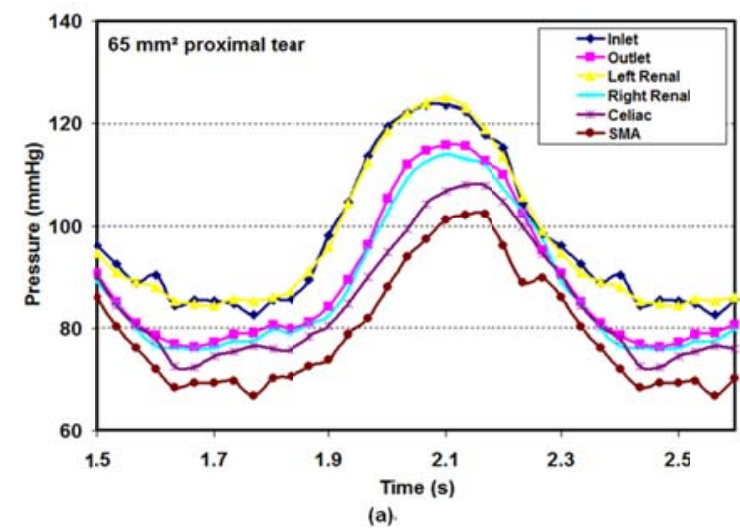

(a)

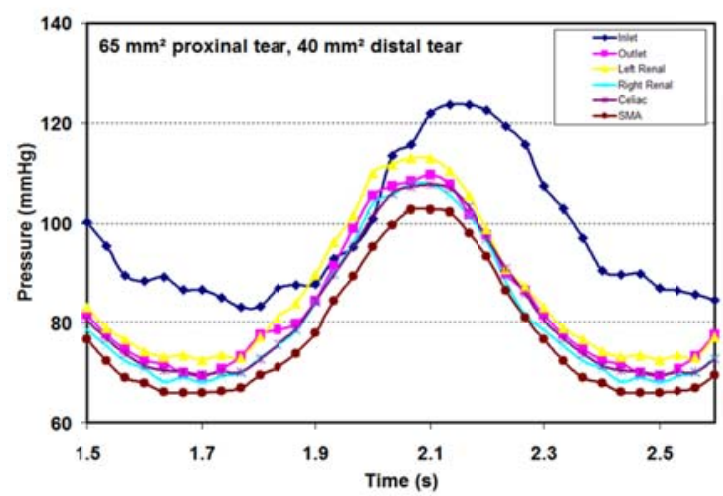

(c)

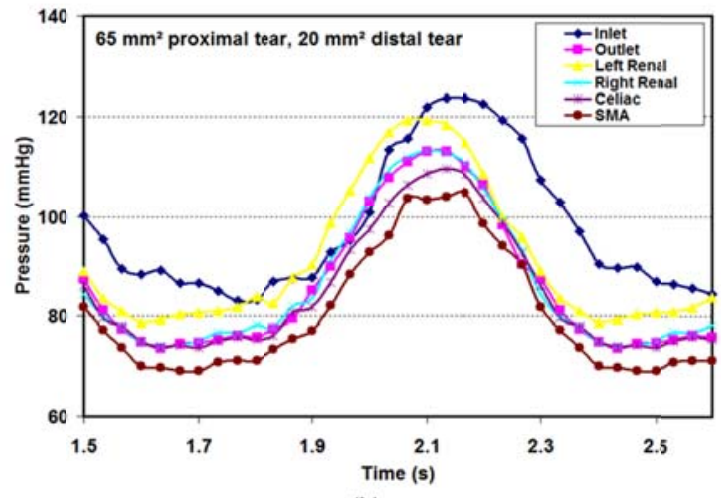

(b).

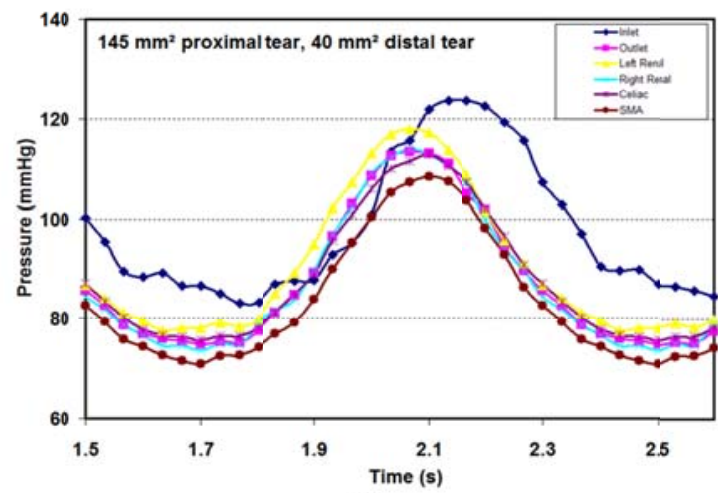

(d)

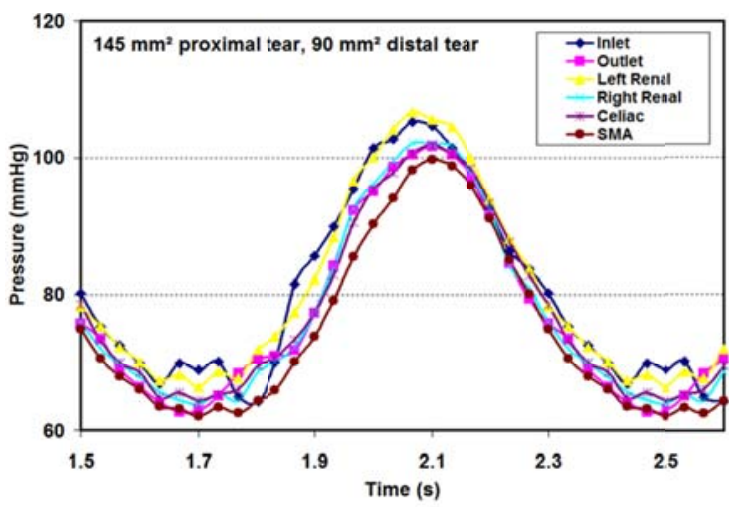

(e)

Figure 2. Different boundary conditions of pressure waveforms. (a) $65 \mathrm{~mm}^{2}$ proximal tear model, (b) $65 \mathrm{~mm}^{2}$ proximal tear, $20 \mathrm{~mm}^{2}$ distal tear model, (c) $65 \mathrm{~mm}^{2}$ proximal tear, $40 \mathrm{~mm}^{2}$ distal tear model, (d) $145 \mathrm{~mm}^{2}$ proximal tear, $40 \mathrm{~mm}^{2}$ distal tear model, and (e) $145 \mathrm{~mm}^{2}$ proximal tear, $90 \mathrm{~mm}^{2}$ distal tear model.

\subsection{Transport equations for the SST k- $\omega$ model}

The SST $k$ - $\omega$ Model has a similar form to the standard $k-\omega$ model and can be written in Cartesian tensor form as: 


$$
\begin{gathered}
\frac{\partial}{\partial t}(\rho k)+\frac{\partial}{\partial x_{i}}\left(\rho k u_{i}\right)=\frac{\partial}{\partial x_{j}}\left(\Gamma_{k} \frac{\partial k}{\partial x_{j}}\right)+\widetilde{G}_{k}-Y_{k}+S_{k} \\
\frac{\partial}{\partial t}(\rho \omega)+\frac{\partial}{\partial x_{i}}\left(\rho \omega u_{i}\right)=\frac{\partial}{\partial x_{j}}\left(\Gamma_{\omega} \frac{\partial \omega}{\partial x_{j}}\right)+G_{\omega}-Y_{\omega}+D_{\omega}+S_{\omega}
\end{gathered}
$$

In these equations, $\rho$ is the density, $t$ is the time, $x$ is the coordinate, $\tilde{G}_{k}$ represents the generation of turbulence kinetic energy due to mean velocity gradients, $G_{\omega}$ represents the generation of $\omega, \Gamma_{k}$ and $\Gamma_{\omega}$ represent the effective diffusivity of $k$ and $\omega$, respectively. $Y_{k}$ and $Y_{\omega}$ represent the dissipation of $k$ and $\omega$ due to turbulence, $D_{\omega}$ represents the cross-diffusion term, $S_{k}$ and $S_{\omega}$ are user-defined source terms. The modeling of these variables is given in the theoretical manual of ANSYS Fluent 15.0 software.

\subsection{Numerical scheme}

We used a finite volume solver (ANSYS Fluent 15.0) to solve the Reynolds averaged Navier-Stokes equations. Secondorder upwind scheme was used for spatial discretization in momentum and turbulence model equations. Moreover, second order implicit scheme was used for transient formulation. Mesh independence tests were carried out and the results showed that the mesh consisting of 150,246 4-Node tetrahedral elements in total with local refinement in the tear region was adequate (see Figure 1b). The Newton-Raphson method was used to solve the discretized equations in the fluid region. The solution was assumed to have converged when the relative change in the dependent variable between two successive time steps was $<10^{-4}$ as shown below:

$$
\sum\left|\lambda_{i, j}^{\gamma+1}-\lambda_{i, j}^{\gamma}\right| / \sum\left|\lambda_{i, j}^{\gamma+1}\right| \leq 10^{-4}
$$

where $\lambda_{i, j}^{\gamma}$ represents any particular dependent variable at time step $\gamma$. All simulations were carried out for four cardiac cycles to achieve a periodic solution, and the results obtained in the fourth cycle are presented here. This cycle was divided into fixed uniform time steps of $0.005 \mathrm{~s}$.

\section{Results}

In this section, we compared our in vitro pressure waveforms in false and true lumens with their numerical predictions. Simulations were carried out for four cardiac cycles to achieve a periodic solution. Synchronized pressure boundary conditions obtained from our in vitro measurements were applied at the inlet and outlet branches of the numerical model. The results presented below are based on the information output in the final cycle.

\subsection{Comparison between experimental and numerical results of $65 \mathrm{~mm}^{2}$ proximal tear and different distal tear size models}

Our numerical scheme was first validated against the in vitro experimental results for $65 \mathrm{~mm}^{2}$ proximal tear and different distal tear size models as shown in Figures 3-5. Pressure was measured in true and false lumens of the in vitro experimental model at a distance of $125 \mathrm{~mm}$ from the top of the aortic arch and was used to validate the values predicted by the numerical model in the same location. Figure 3 shows a good correlation between the numerical and in vitro experimental results of $65 \mathrm{~mm}^{2}$ proximal tear model (maximum relative error true lumen $3.8 \%$, false lumen $0.85 \%$ ). The effect of the distal tear presence of $20 \mathrm{~mm}^{2}$ and $40 \mathrm{~mm}^{2}$ on the pressure waveforms in both true and false lumens were depicted in Figure 4 and Figure 5, respectively. Excellent correlation was obtained between the pressure results in true and false lumens as shown in Figure 5 and Figure 6. 

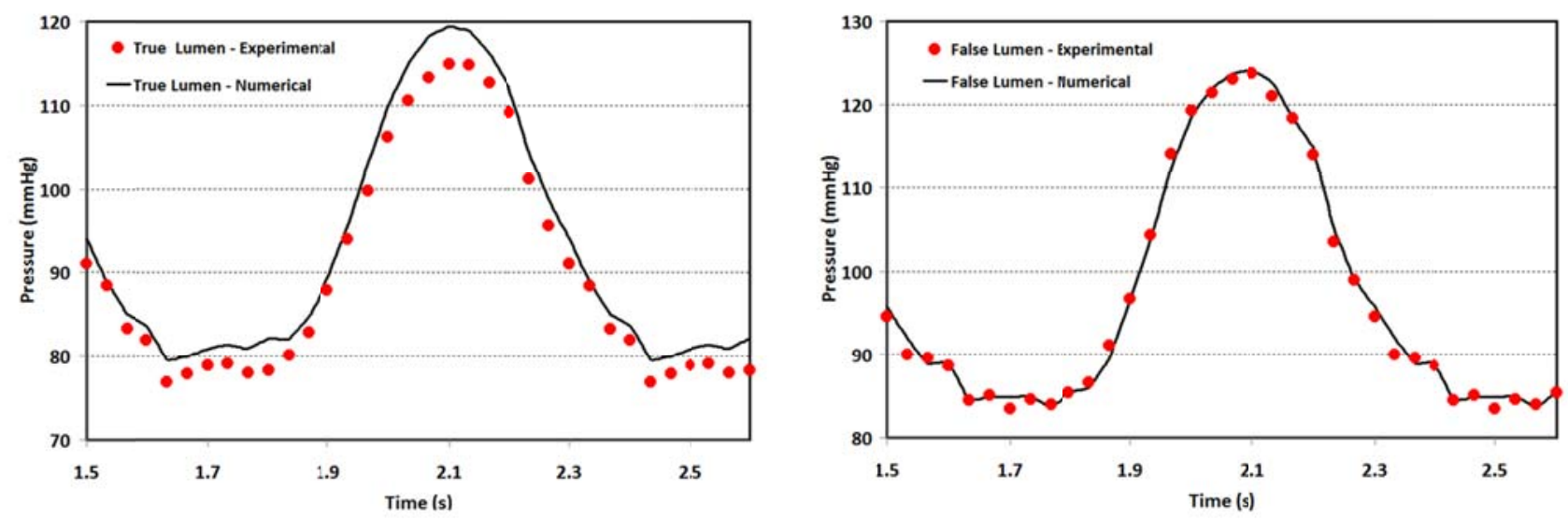

Figure 3. Comparison of the pressure in true and false lumens between experimental and numerical results (proximal tear $=65 \mathrm{~mm}^{2}$, distal tear $=0 \mathrm{~mm}^{2}$ )
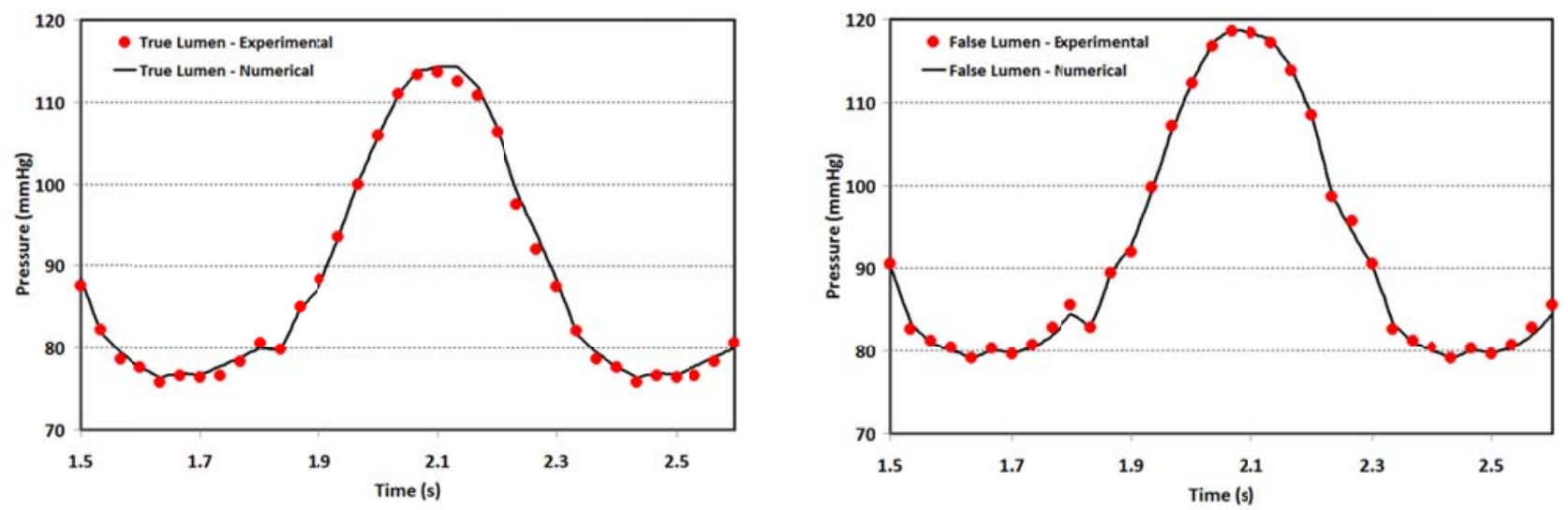

Figure 4. Comparison of the pressure in true and false lumens between experimental and numerical results (proximal tear $=65 \mathrm{~mm}^{2}$, distal tear $=20 \mathrm{~mm}^{2}$ )
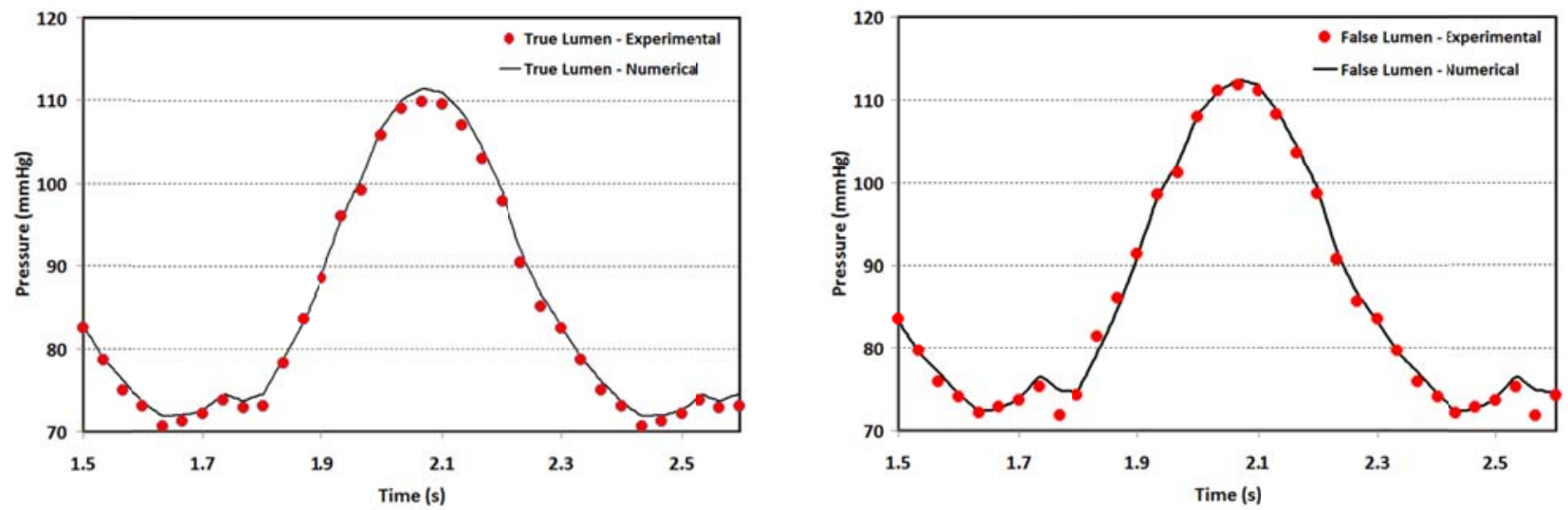

Figure 5. Comparison of the pressure in true and false lumens between experimental and numerical results (proximal tear $=65 \mathrm{~mm}^{2}$, distal tear $=40 \mathrm{~mm}^{2}$ ) 


\subsection{Comparison between experimental and numerical results of $145 \mathbf{~ m m}^{2}$ proximal tear and different distal tear size models}

Figure 6 showed an excellent correlation between experimental and numerical results of the pressure values in false and true lumens for a proximal tear of $145 \mathrm{~mm}^{2}$ and a distal tear of $40 \mathrm{~mm}^{2}$ (maximum relative error true lumen $1.39 \%$, false lumens 3.68\%). Figure 7 illustrated an excellent correlation between numerical and experimental results for proximal $\left(145 \mathrm{~mm}^{2}\right)$ and distal $\left(90 \mathrm{~mm}^{2}\right)$ tears scenario (maximum relative error true lumen $5.1 \%$, false lumen $6.9 \%$ ).
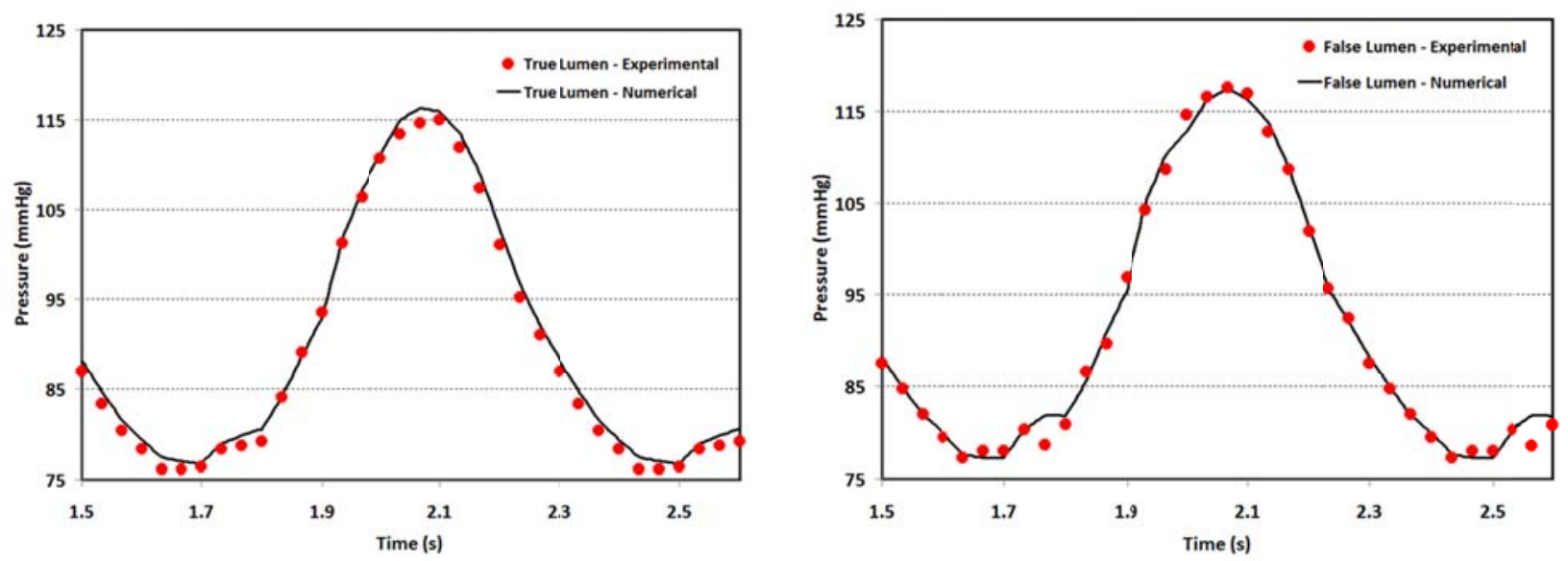

Figure 6. Comparison of the pressure in true and false lumens between experimental and numerical results (proximal tear $=145 \mathrm{~mm}^{2}$, distal tear $=40 \mathrm{~mm}^{2}$ )

As the proximal tear size increased from $65 \mathrm{~mm}^{2}$ (see Figure 5) to $145 \mathrm{~mm}^{2}$ (see Figure 6), the peak systolic pressure increased by $4.8 \mathrm{mmHg}$ and the end diastolic pressure increased by $4.9 \mathrm{mmHg}$ in true lumen. Similarly, Figure 6 illustrated that peak systolic pressure increased by $4.9 \mathrm{mmHg}$ and the end diastolic pressure increased by $4.95 \mathrm{mmHg}$ in false lumen. This increase in the pressure in both lumens was associated with an increase in the mass flow rate through the proximal tear when the tear size increased from $65 \mathrm{~mm}^{2}$ to $145 \mathrm{~mm}^{2}$. As the distal tear increased to $90 \mathrm{~mm}^{2}$, Figure 7 showed reduction in the pressure for both lumens compared with pressure values in Figure 6.
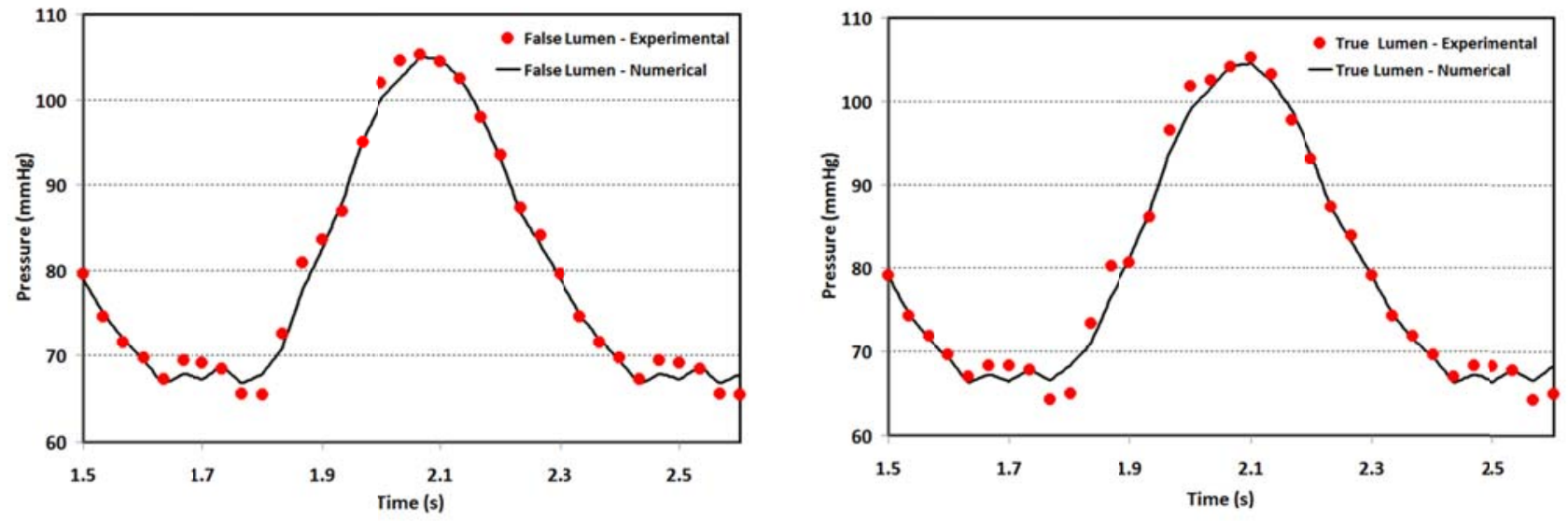

Figure 7. Comparison of the pressure in true and false lumens between experimental and numerical results (proximal tear $=145 \mathrm{~mm}^{2}$, distal tear $=90 \mathrm{~mm}^{2}$ ) 


\section{Discussions}

The present CFD tool was validated in different bench-top models of aortic dissection models representing different scenarios of proximal and distal tears. The numerical results were in excellent correlation with our in vitro measurements of pressure waveforms in true and false lumens. This study showed that CFD tools have a potential role to correctly capture the main features of pressure traces recorded in vitro of type B aortic dissection with various tear size and location.

\section{Acknowledgments}

This work was supported by the Frankel Vascular Research Fund.

\section{References}

[1] Fann JI, Miller DC. Aortic dissection. Ann. Vascular Surg. 1995; 9: 311-23. PMid:7632561. http://dx.doi.org/10.1007/BF02135293

[2] Czermak BV, Waldenberger P, Fraedrich G, et al. Treatment of stanford type B aortic dissection with stent-grafts: preliminary results. Radiology. 2000; 217: 544-50. PMid:11058658. http://dx.doi.org/10.1148/radiology.217.2.r00oc16544

[3] Tsai TT, Nienaber CA, Eagle KA. Acute aortic syndromes. Circulation. 2005; 112: 3802-13. PMid:16344407. http://dx.doi.org/10.1161/CIRCULATIONAHA.105.534198

[4] Chung S, Vafai K. Effect of the fluid-structure interactions on low-density lipoprotein within a multi-layered arterial wall. J. Biomechanics. 2012; 45: 371-81. PMid:22153222. http://dx.doi.org/10.1016/j.jbiomech.2011.10.002

[5] Khamdaengyodtai P, Vafai K, Sakulchangsatjatai P, et al. Effects of pressure on arterial failure. J. Biomechanics. 2012; 45: 2577-88. PMid:22980577. http://dx.doi.org/10.1016/j.jbiomech.2012.07.032

[6] Chung S, Vafai K. Low-density lipoprotein transport within a multi-layered arterial wall-effect of the atherosclerotic plaque/stenosis. J. Biomechanics. 2013; 46: 574-85. PMid:23089456. http://dx.doi.org/10.1016/j.jbiomech.2012.09.022

[7] Chung S, Vafai K. Mechanobiology of low-density lipoprotein transport within an arterial wall-impact of hyperthermia and coupling effects. J. Biomechanics. 2014; 47: 137-7. PMid:24183548. http://dx.doi.org/10.1016/j.jbiomech.2013.09.030

[8] Wang S, Vafai K. Analysis of low density lipoprotein (LDL) transport within a curved artery. Annals Biomed Eng. 2015; 43(7): 1571-84. PMid:25527319. http://dx.doi.org/10.1007/s10439-014-1219-x

[9] Lasiello M, Vafai K, Andreozzi A, et al. Effects of external and internal hyperthermia on LDL transport and accumulation within an arterial wall in the presence of stenosis. Annals Biomed Eng. 2015; 43(7): 1585-99. PMid:25520050. http://dx.doi.org/10.1007/s10439-014-1196-0

[10] Ricotta JJ, Pagan J, Xenos M, et al. Cardiovascular disease management: the need for better diagnostics. Med Biol Eng Comput. 2008; 46: 1059-68. PMid:19002517. http://dx.doi.org/10.1007/s11517-008-0416-x

[11] Wen CY, Yang AS, Tseng LY, et al. Investigation of pulsatile flowfield in healthy thoracic aorta models. Ann Biomed Eng. 2010; 38: 391-402. PMid:19890715. http://dx.doi.org/10.1007/s10439-009-9835-6

[12] Jung J, Hassanein A, Lyczkowski RW. Hemodynamic computation using multiphase flow dynamics in a right coronary artery. Ann Biomed Eng. 2006; 34: 393-407. PMid:16477502. http://dx.doi.org/10.1007/s10439-005-9017-0

[13] Steinman D. Image-based computational fluid dynamics modeling in realistic arterial geometries. Ann Biomed Eng. 2000; 30: 483-97. http://dx.doi.org/10.1114/1.1467679

[14] Baek H, Jayaraman M, Karniadakis GE. Wall stress and pressure distribution on aneurysms and infundibulae in hte posterior communicating artery bifurcation. Ann Biomed Eng. 2009; 37: 2469-87. PMid:19757058.

http://dx.doi.org/10.1007/s10439-009-9794-y

[15] Gardhagen R, Renner J, Lanne T, et al. Subject specific wall shear stress in the human thoracic aorta. WSEAS Trans Biol Biomed. 2006; 3: 609-14.

[16] Tse KM, Chiu P, Lee HP, et al. Investigation of hemodyanmics in the development of dissecting aneurysm within patient-specific dissecting aneurismal aortas using computational fluid dynamics (CFD) simulations. J. Biomech. 2010; 44: 827-36. PMid:21256491. http://dx.doi.org/10.1016/j.jbiomech.2010.12.014

[17] Fan Y, Cheng SWK, Qing KX, et al. Endovascular repair of type B aortic dissection: a study by computational fluid dynamics. J. Biomedical Science and Engineering. 2010; 3: 900-7. http://dx.doi.org/10.4236/jbise.2010.39120

[18] Soudah E, Rudenick P, Bordone M, et al. Validation of numerical flow simulations against in vitro phantom measurements in different type B aortic dissection scenarios. Comput Methods Biomech Biomed Engin. 2015; 18(8): 805-15. PMid:24156535. http://dx.doi.org/10.1080/10255842.2013.847095 
[19] Rudenick PA, Bijnens BH, García-Dorado D, et al. An in vitro phantom study on the influence of tear size and configuration on the hemodynamics of the lumina in chronic type B aortic dissections. J. Vasc Surg. 2013; 57: 464-74. PMid:23141674. http://dx.doi.org/10.1016/j.jvs.2012.07.008

[20] Karmonik C, Bismuth J, Shah DJ, et al. Computational study of hemodynamic effects of entry- and exit-tear coverage in a DeBakey type III aortic dissection: technical report. Eur J Vasc Endovasc Surg. 2011; 42: 172-7. PMid:21549622. http://dx.doi.org/10.1016/j.ejvs.2011.04.008

[21] Khanafer K, Berguer R. Fluid-structure interaction analysis of turbulent pulsatile flow within a layered aortic wall as related to aortic dissection. J. Biomech. 2009; 42: 2642-8. PMid:19765711. http://dx.doi.org/10.1016/j.jbiomech.2009.08.010

[22] Grinberg L, Yakhot A, Karniadakis GK. Analyzing transient turbulence in a stenosed carotid artery by proper orthogonal decomposition. Ann Biomed Eng. 2009; 37: 2200-17. PMid:19669884. http://dx.doi.org/10.1007/s10439-009-9769-z

[23] Khanafer K, Bull J, Upchurch G, et al. Turbulence significantly increases pressure and fluid shear stress in an aortic aneurysm model under resting and exercise flow conditions. Ann Vasc Surg. 2007; 21: 67-74. PMid:17349339. http://dx.doi.org/10.1016/j.avsg.2006.10.009

[24] Berguer R, Bull JL, Khanafer K. Refinements in mathematical models to predict aneurysm growth and rupture. Ann. N.Y. Acad. Sci. 2006; 1085: 110-6. PMid:17182927. http://dx.doi.org/10.1196/annals.1383.033

[25] Menter FR. Two-equation eddy-viscosity turbulence models for engineering applications. AIAA J. 1994; 32: 1598 -1605. http://dx.doi.org/10.2514/3.12149

[26] Wilcox DC. Simulation of transition with a two-equation turbulence model. AIAA J. 1994; 32: 247-55. http://dx.doi.org/10.2514/3.59994

[27] Jones WP, Launder BE. Prediction of laminarization with a 2-equation model of turbulence. Int J Heat Mass Tran. 1972; 15: 301-14. http://dx.doi.org/10.1016/0017-9310(72)90076-2

[28] Wang K, Tavakkoli F, Wang S, et al. Analysis and analytical charcterization of bioheat transfer during radiofrequency ablation. J. Biomech. 2015; 48, 930-40. PMid:25769731. http://dx.doi.org/10.1016/j.jbiomech.2015.02.023 